\title{
Interrelationships Between the Enzymes of Ethanolamine Metabolism in Escherichia coli
}

\author{
By PETER W. JONES† AND JOHN M. TURNER* \\ Department of Biochemistry, University of Liverpool, PO Box 147, Liverpool L69 3BX, UK
}

(Received 9 May 1983; revised 29 July 1983)

\begin{abstract}
The activities of the enzymes ethanolamine ammonia-lyase, CoA-dependent and CoAindependent aldehyde dehydrogenases, and isocitrate lyase were assayed in Escherichia coli which had been grown on various sources of carbon and nitrogen. Induction of ethanolamine ammonia-lyase and of maximal levels of both aldehyde dehydrogenases required the concerted effects of ethanolamine and vitamin (or coenzyme) $B_{12}$. Molecular exclusion chromatography revealed that, in the absence of one or both co-inducers, two repressible isoenzymes of CoAdependent aldehyde dehydrogenase (mol. wts 900000 and 120000) were produced, these being replaced by two inducible isoenzymes (mol. wts 520000 and 370000 ) in the presence of both coinducers. A similar inducible repressible series of isoenzymes was also observed for CoAindependent aldehyde dehydrogenase. No evidence was found for structural relationships between ethanolamine ammonia-lyase, CoA-dependent aldehyde dehydrogenase and CoAindependent aldehyde dehydrogenase, but mutant and physiological studies demonstrated that the induction of the first two enzymes is under common control. Evidence is presented for the operation of a previously unreported pathway of ethanolamine metabolism in $E$. coli.
\end{abstract}

\section{INTRODUCTION}

A number of bacterial enzymes are known to act on the amino alcohol ethanolamine. Catabolism of ethanolamine may be initiated by ethanolamine oxidase (EC 1.4.3.8) (Narrod \& Jakoby, 1964), ethanolamine ammonia-lyase (EC 4.3.1.7) (Bradbeer, 1965), or by a biodegradative ethanolamine kinase (EC 2.7.1.82)-ethanolamine-o-phosphate phospholyase (EC 4.2.99.7) pathway (Jones \& Turner, 1971). The principal routes of metabolism of the resultant aldehydes are catalysed by CoA-dependent (EC 1.2.1.10) or CoA-independent (EC 1.2.1.3) forms of aldehyde dehydrogenase. Previous inter-species studies suggested that ethanolamine catabolism initiated by ethanolamine ammonia-lyase activity was associated with the CoAdependent enzyme, whereas ethanolamine kinase- or ethanolamine oxidase-initiated metabolism was associated with the CoA-independent enzyme (Shukla \& Turner, 1980).

In Escherichia coli, ethanolamine is cleaved to acetaldehyde and ammonia by the cobamidedependent enzyme ethanolamine ammonia-lyase (Blackwell et al., 1976). Synthesis of this enzyme requires the combined presence of both the substrate (ethanolamine) and the cofactor (adenosylcobalamin, coenzyme $\mathbf{B}_{12}$ ), a phenomenon known as concerted induction (Blackwell et al., 1977). The E. coli enzyme has a molecular weight of approximately 540000 , and is composed of six small (mol. wt 35200), probably catalytic subunits and six large (mol. wt 56900), probably regulatory subunits (Pennington et al., 1981). We report here evidence for the common regulation of ethanolamine ammonia-lyase and CoA-dependent aldehyde dehydrogenase in $E$. coli.

† Present address: Botany Department, University College, Cork, Ireland.

Abhreriation: LSD, Least significant difference. 


\section{METHODS}

Growth conditions and media. The mineral composition of the basal medium was as previously described (Scarlett \& Turner, 1976). Cobalamin was supplied, where necessary, as vitamin $B_{12}$ (cyanocobalamin; $40 \mu \mathrm{g} \mathrm{l}^{-1}$ ), which is readily converted to coenzyme $B_{12}$ (adenosylcobalamin) by E. coli. Quantitative and qualitative variations of the carbon and nitrogen sources are detailed in the text and in Table and Figure legends. Cultures (100 ml volume) were grown in $250 \mathrm{ml}$ Erlenmeyer flasks at $30^{\circ} \mathrm{C}$ on an orbital incubator (100 r.p.m., radius of gyration $25 \mathrm{~mm}$ ).

Bacteria. Escherichia coli strains NCIB 8114, NCIB 9484 (strain B) and NCIB 8797 (strain K12) were obtained from the National Collection of Industrial and Marine Bacteria, Aberdeen, UK. The constitutive mutant strain, NCIB 11361, was derived from strain NCIB 8114 (Blackwell \& Turner, 1978). After mutagenesis of strain NCIB 8114 for $10 \mathrm{~min}$ at $37^{\circ} \mathrm{C}$ with $1 \%(\mathrm{v} / \mathrm{v})$ ethyl methanesulphonate, mutant strain PDT 74 was isolated by selection for cobamide-independent growth on ethanolamine as the sole nitrogen source.

Preparation of cell-free extracts. Growth of $E$. coli cultures was followed by measuring $\mathrm{OD}_{540}^{1} \mathrm{~cm}$, and cells were harvested at optical density values between 0.90 and 0.95 . The cells were washed and then resuspended in $5 \mathrm{ml}$ $0.02 \mathrm{M}$-Tris/ $\mathrm{HCl}, \mathrm{pH} \mathrm{7.5}$, and then disrupted using an ultrasonic disintegrator $(10 \times 10 \mathrm{~s}$ exposures, amplitude 12 $16 \mu \mathrm{m}$, with $50 \mathrm{~s}$ intervals between disintegrations), the sonication vessel being cooled in crushed ice throughout the extraction procedure. The suspension was then centrifuged at $100000 \mathrm{~g}$ for $1 \mathrm{~h}$ at $2{ }^{\circ} \mathrm{C}$, and the resultant supernatant was used as the source of enzymes.

Molecular exclusion chromatography. A column of Bio-Gel A-1.5m (Bio-Rad Laboratories) $\left(V_{\mathrm{t}}=229.4 \mathrm{ml}\right.$, $\left.V_{0}=68.7 \mathrm{ml}\right)$ was equilibrated with $0.1 \mathrm{M}-\mathrm{Tris} / \mathrm{HCl}$ buffer, $\mathrm{pH} 7 \cdot 5$, containing $20 \%(\mathrm{v} / \mathrm{v})$ glycerol, $10 \mathrm{mM}-$ potassium chloride and $4 \mathrm{~mm}$-dithiothreitol. The sample $(100-120 \mathrm{mg}$ protein in a cell-free extract unless stated otherwise) was loaded onto the column and eluted at $50 \mathrm{~mm}$ hydrostatic pressure, with a flow rate of $12-15 \mathrm{ml} \mathrm{h}^{-1}$. Fractions ( $1 \mathrm{ml}$ volume) were collected and assayed for enzyme activities and protein content. The column was calibrated using standard markers of known spherical molecular weight, namely blue dextran (mol. wt 2 million), thyroglobulin (650000), jackbean urease (483000), beef catalase (236000), yeast alcohol dehydrogenase $(146000)$, $E$. coli alkaline phosphatase $(80000)$ and cytochrome $c(12400)$. Elution data were plotted as $K_{\text {av }}$ (i.e. $\left.\mathrm{V}_{\mathrm{e}}-V_{0} / V_{\mathrm{t}}-V_{0}\right)$ against $\log _{10}(\mathrm{~mol}$. wt).

Anion-exchange chromatography. DEAE-cellulose (Whatman) was charged according to the manufacturer's instructions. A column $(17.2 \times 4.0 \mathrm{~cm})$ was poured and equilibrated with $0.05 \mathrm{M}$-Tris/ $\mathrm{HCl}$ buffer, $\mathrm{pH} \mathrm{7.9,}$ containing $20 \%$ glycerol and $4 \mathrm{mM}$-dithiothreitol. The enzyme sample was dialysed overnight against the equilibrating buffer. After loading the sample and washing the column with the equilibrating buffer, bound protein was eluted from the column with a $500 \mathrm{ml}$ linear 0-0.5 M-potassium chloride gradient. Fractions ( $5 \mathrm{ml}$ volume) were collected and assayed for potassium chloride concentration (conductivity), enzyme activities and protein content.

Assays. Ethanolamine ammonia-lyase activity was usually assayed by the colorimetric method of Scarlett \& Turner (1976), with the added precaution of $5 \mathrm{~mm}$-iodoacetamide in the reaction buffer to block aldehyde dehydrogenase activity. In fractions from the Bio-Gel column, ethanolamine ammonia-lyase activity was assayed by the spectrophotometric method (Blackwell \& Turner, 1978).

The activity of CoA-dependent aldehyde dehydrogenase was assayed at pH 7.6 by the method of Rudolph et al. (1968) and that of CoA-independent aldehyde dehydrogenase at pH $9 \cdot 1$ by the method of Jakoby (1958). Both aldehyde dehydrogenase assays incorporated controls to correct for the activity of other dehydrogenases in the enzyme preparations. Isocitrate lyase was assayed by the method of Dixon \& Kornberg (1959); ethanolamine oxidase by the method of Narrod \& Jakoby (1964); and ethanolamine-o-phosphate phospholyase by the method of Jones \& Turner (1973). Protein concentration was determined using the biuret method (Gornall et al., 1949).

All enzyme activities are expressed as nmol substrate converted $\min ^{-1}\left(\mathrm{mg} \mathrm{protein}^{-1} \mathrm{or}(\mathrm{ml} \text { fraction })^{-1}\right.$ under the prevailing assay conditions.

Statistical analysis. The data presented in Tables 1-3 were obtained from experiments laid out in totally randomized designs, with four replicates of each treatment. The data were assessed using a standard analysis of variance procedure and are presented as the mean value of four replicate cultures for each treatment, with the corresponding values for the least significant difference at the $5 \%$ level (i.e. LSD $5 \%$ ) for each experiment. All other experiments were performed at least three times and the mean data are presented.

\section{RESULTS}

\section{Effects of carbon and nitrogen sources on enzyme activity profiles}

The activities of four enzymes involved in ethanolamine metabolism [ethanolamine ammonia-lyase, isocitrate lyase (EC 4.1.3.1) and CoA-dependent and CoA-independent aldehyde dehydrogenases] were assayed in $E$. coli strains supplied with different carbon and nitrogen sources. Activity of isocitrate lyase was assayed to identify the operation of the glyoxylate pathway of acetate utilization. 
Table 1. Effects of carbon and nitrogen sources on the activities of enzymes of ethanolamine catabolism in E. coli strain NCIB 8114

Concentrations were as follows: glycerol, $5 \mathrm{~g} \mathrm{I}^{-1}$; sodium acetate, $5 \mathrm{~g}^{-1}$; ammonium sulphate, $1 \mathrm{~g}^{-1}$; 1 -amino propan-2-ol, $1 \mathrm{~g} \mathrm{l}^{-1}$; vitamin $\mathrm{B}_{12}, 40 \mu \mathrm{g} \mathrm{l}^{-1}$. Ethanolamine was supplied at $5 \mathrm{~g} \mathrm{l}^{-1}$ (denoted by *) or $1 \mathrm{~g}^{-1}$. The mineral composition of the medium was as described previously (Scarlett \& Turner, 1976).

Nitrogen + carbon sources

Ammonium sulphate + glycerol

Ammonium sulphate + ethanolamine

+ glycerol

Ammonium sulphate + vitamin $B_{12}$

+ glycerol

Ammonium sulphate + ethanolamine

+ vitamin $\mathbf{B}_{12}+$ glycerol

Ethanolamine + vitamin $\mathbf{B}_{12}$

+ glycerol

Ammonium sulphate + sodium acetate

Ethanolamine + vitamin $\mathbf{B}_{12}+$ sodium acetate

Ethanolamine* + vitamin $\mathbf{B}_{12}$

Ammonium sulphate + 1-amino-propan-2-ol

+ vitamin $\mathrm{B}_{12}+$ glycerol

Ammonium sulphate + 1-amino-propan-2-ol

+ glycerol

LSD $5 \%$
Enzyme activities [nmol substrate converted $\mathrm{min}^{-1}$ (mg protein $)^{-1}$ ]

\begin{tabular}{|c|c|c|c|}
\hline $\begin{array}{l}\text { Ethanolamine } \\
\text { ammonia-lyase }\end{array}$ & $\begin{array}{l}\text { CoA-dependent } \\
\text { aldehyde } \\
\text { dehydrogenase }\end{array}$ & $\begin{array}{l}\text { CoA-independent } \\
\text { aldehyde } \\
\text { dehydrogenase }\end{array}$ & $\begin{array}{c}\text { Isocitrat } \\
\text { lyase }\end{array}$ \\
\hline 0 & $24 \cdot 7$ & $9 \cdot 1$ & $1 \cdot 1$ \\
\hline 0 & 22.8 & 7.4 & 0.6 \\
\hline 0 & $25 \cdot 3$ & $10 \cdot 3$ & $1 \cdot 2$ \\
\hline $77 \cdot 4$ & $72 \cdot 0$ & $33 \cdot 1$ & 1.4 \\
\hline 78.9 & $73 \cdot 2$ & 29.9 & $1 \cdot 1$ \\
\hline 0 & 16.8 & $4 \cdot 6$ & 86.9 \\
\hline $35 \cdot 5$ & $28 \cdot 6$ & $16 \cdot 1$ & $90 \cdot 1$ \\
\hline $49 \cdot 4$ & 51.6 & $46 \cdot 1$ & $70 \cdot 3$ \\
\hline $43 \cdot 5$ & $42 \cdot 0$ & $18 \cdot 2$ & 0.8 \\
\hline 0 & 23.5 & 8.6 & 1.0 \\
\hline $8 \cdot 1$ & $6 \cdot 2$ & 6.8 & $5 \cdot 3$ \\
\hline
\end{tabular}

Cultures of E. coli NCIB 8114, grown with ammonium sulphate $\left(\mathrm{g} \mathrm{l}^{-1}\right)$ as the nitrogen source and glycerol $\left(5 \mathrm{~g} \mathrm{l}^{-1}\right)$ as the carbon source, exhibited significant activity of only the CoAdependent and CoA-independent aldehyde dehydrogenases (Table 1). With nitrogen provided by ethanolamine $\left(1 \mathrm{~g} \mathrm{l}^{-1}\right)$, in the presence of vitamin $B_{12}$ (cyanocobalamin; $40 \mu \mathrm{g}^{-1}$ ), and carbon supplied as glycerol, increased activities of both aldehyde dehydrogenases were exhibited, while high levels of ethanolamine ammonia-lyase activity were also induced (Table 1).

Considerable differences were found between the corresponding enzyme activities in various strains of E. coli. Strain NCIB 8114 exhibited ethanolamine ammonia-lyase and CoAdependent aldehyde dehydrogenase activities approximately eightfold greater than those of K12 strains, e.g. NCIB 8797. The two strains exhibited similar rates of cobamide-dependent growth on ethanolamine as the major source of nitrogen, and no significant differences could be detected between the strains with respect to enzyme-substrate or cofactor affinities, enzyme stabilities or to isocitrate lyase activity (P. W. Jones \& J. M. Turner, unpublished results).

The presence of ammonium sulphate $\left(\mathrm{g} \mathrm{l}^{-1}\right)$ in the growth medium had no inhibitory effect on enzyme induction due to ethanolamine and vitamin $\mathbf{B}_{12}$ (Table 1). Replacement of glycerol $\left(5 \mathrm{~g}^{-1}\right)$ by sodium acetate $\left(5 \mathrm{~g}^{-1}\right)$ as the principal carbon source resulted in the marked induction of isocitrate lyase activity (Table 1) and in the partial repression of the other three enzymes (Table 1). The repressive effect of acetate on the induction of these enzymes was also obtained by the addition of acetate to mid-exponential phase cultures growing with glycerol $\left(5 \mathrm{~g} \mathrm{l}^{-1}\right)$, ethanolamine $\left(1 \mathrm{~g} \mathrm{l}^{-1}\right)$ and vitamin $\mathrm{B}_{12}$ (Fig. 1), and could be reversed by the addition of exogenous cyclic AMP. Replacement of acetate by a number of sugars, including glucose, maltose and lactose, also resulted in catabolite-repression of ethanolamine ammonia-lyase and both aldehyde dehydrogenases. 


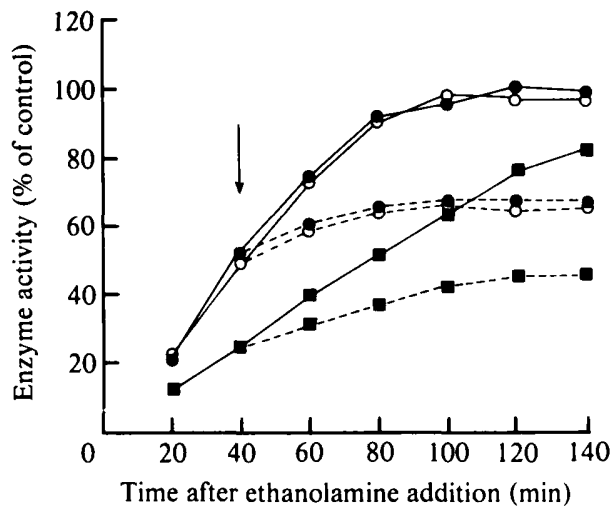

Fig. 1

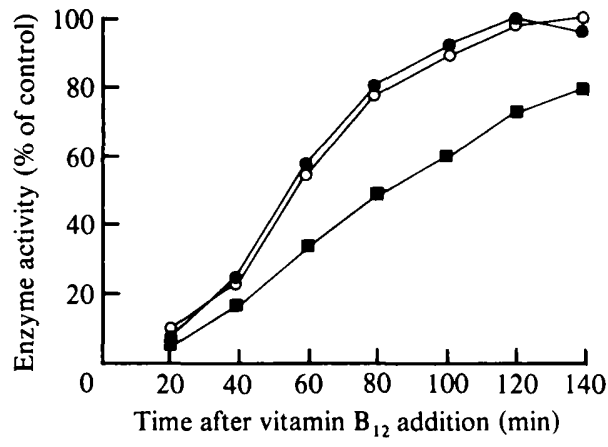

Fig. 2

Fig. 1. Time courses (solid lines) for induction of ethanolamine ammonia-lyase (O), CoA-dependent aldehyde dehydrogenase $(O)$ and CoA-independent aldehyde dehydrogenase $(\square)$ by addition of ethanolamine to $E$. coli strain NCIB 8114. Cultures were grown to mid-exponential phase in medium containing glycerol $\left(5 \mathrm{~g} \mathrm{l}^{-1}\right)$, ammonium sulphate $\left(\mathrm{g} \mathrm{l}^{-1}\right)$ and vitamin $\mathrm{B}_{12}\left(40 \mu \mathrm{g} \mathrm{l}^{-1}\right)$, at which point (time zero) ethanolamine was added aseptically to a final concentration of $1 \mathrm{~g} \mathrm{l}^{-1}$. Enzyme activity is presented as the percentage of the corresponding activity in the control cultures growing, from inoculation, in medium containing ammonium sulphate, glycerol and both co-inducers. Addition of sodium acetate to a final concentration of $5 \mathrm{~g}^{-1}$ at time $40 \mathrm{~min}$ (indicated by an arrow) resulted in partial repression of induction (broken lines).

Fig. 2. Time courses for induction of ethanolamine ammonia-lyase ( $\odot)$, CoA-dependent aldehyde dehydrogenase $(O)$ and $C o A$-independent aldehyde dehydrogenase $(\omega)$ by addition of vitamin $B_{12}$ to $E$. coli strain NCIB 8114. Cultures were grown to mid-exponential phase in medium containing glycerol $\left(5 \mathrm{~g}^{-1}\right)$, ammonium sulphate $\left(\mathrm{g}^{-1}\right)$ and ethanolamine $\left(\mathrm{g} \mathrm{l}^{-1}\right)$, at which point (time zero) vitamin $B_{12}$ was added aseptically to a final concentration of $40 \mu \mathrm{g}^{-1}$. Enzyme activity is presented as the percentage of the corresponding activity in the control cultures growing, from inoculation, in medium containing ammonium sulphate, glycerol and both co-inducers.

Growth of strain NCIB 8114 with non-limiting levels of ethanolamine $\left(5 \mathrm{~g}^{-1}\right)$, plus vitamin $B_{12}$, as both the carbon and nitrogen source, produced an enzyme profile different from that obtained when the carbon source was glycerol (Table 1). Compared to glycerol-grown cultures, the activities of ethanolamine ammonia-lyase and CoA-dependent aldehyde dehydrogenase were reduced, due in part to the elevated ionic concentration of the high-ethanolamine medium (P. W. Jones \& J. M. Turner, unpublished results), while CoA-independent aldehyde dehydrogenase activity was increased and a high level of isocitrate lyase activity was induced. Growth of NCIB 8114 with ethanolamine as the carbon source was strictly cobamide-dependent, and no activity was detected of any of the cobamide-independent enzymes of bacterial ethanolamine metabolism. Not all strains of $E$. coli were capable of cobamide-dependent growth with ethanolamine as the sole source of carbon and nitrogen. Strains NCIB 8114 and 8797 grew whereas strain NCIB 9484 failed to grow under these conditions, though no association could be determined between levels of the enzymes of ethanolamine metabolism under investigation and the ability to grow on this medium.

A mutant (PDT 74) of strain NCIB 8114 was isolated which, with glycerol $\left(5 \mathrm{~g}^{-1}\right)$ as the major carbon source, could utilize ethanolamine as the nitrogen source in the absence of vitamin $B_{12}$. Under these conditions, a very high level of CoA-independent aldehyde dehydrogenase activity was induced (Table 2), while the activity of the CoA-dependent enzyme was similar to that of the parental strain (NCIB 8114) grown with glycerol $\left(5 \mathrm{~g} \mathrm{l}^{-1}\right)$, ethanolamine $\left(5 \mathrm{~g} \mathrm{l}^{-1}\right)$ and ammonium sulphate $\left(\mathrm{g} \mathrm{I}^{-1}\right)$ (P. W. Jones \& J. M. Turner, unpublished results). No ethanolamine ammonia-lyase activity could be detected, nor was there any cross-reaction between material in the preparation and antiserum to pure $E$. coli ethanolamine ammonia-lyase (Blackwell \& Turner, 1978). No evidence was found for the operation of either the ethanolamine oxidase or the ethanolamine kinase-phospholyase pathways in PDT 74, these being the two 
Table 2. Activities of enzymes of ethanolamine catabolism in E. coli strain PDT 74 under various growth conditions

Concentrations of ethanolamine $\left(\mathrm{g} \mathrm{l}^{-1}\right)$ are given in parentheses. Glycerol and sodium acetate were supplied at $5 \mathrm{gl}^{-1}$ and vitamin $\mathrm{B}_{12}$ at $40 \mu \mathrm{g} \mathrm{l}^{-1}$.

Enzyme activities [nmol substrate converted min $^{-1}$
(mg protein) $^{-1}$ ]

cobamide-independent methods of ethanolamine catabolism reported in bacteria. When supplied with ethanolamine, plus vitamin $B_{12}$, as the nitrogen source, PDT 74 exhibited an enzyme profile similar to that of the parental strain (NCIB 8114) (Table 2). The cobamideindependent metabolism of ethanolamine by strain PDT 74 could not support cell growth when ethanolamine served as the sole source of carbon, in either the presence or absence of ammonium sulphate $\left(1 \mathrm{~g} \mathrm{l}^{-1}\right)$.

\section{Investigation of the relationship between ethanolamine ammonia-lyase and CoA-dependent aldehyde dehydrogenase}

The requirements for induction of ethanolamine ammonia-lyase have been described previously (Blackwell \& Turner, 1978); namely the presence of both ethanolamine and vitamin $B_{12}$. Here, induction requirements for this enzyme were compared with those for the CoAdependent and CoA-independent forms of aldehyde dehydrogenase in strain NCIB 8114. Unlike ethanolamine ammonia-lyase, both aldehyde dehydrogenases exhibited significant levels of activity in the absence of ethanolamine and vitamin $B_{12}$, but maximum induction of both enzymes required the combined effect of ethanolamine and vitamin $B_{12}$ (Table 1). For all three enzymes, coenzyme $B_{12}$ (adenosylcobalamin) could replace vitamin $B_{12}$ as co-inducer (P. W. Jones \& J. M. Turner, unpublished results), but the light-and temperature-stability of the former precluded its general use.

Time courses for the induction of these enzymes were obtained by growing cultures of strain NCIB 8114 to mid-exponential phase in medium lacking either one or the other co-inducer, with ammonium sulphate $\left(\mathrm{g} \mathrm{l}^{-1}\right)$ as the nitrogen source and glycerol $\left(5 \mathrm{~g} \mathrm{l}^{-1}\right)$ as the carbon source; the missing co-inducer was then added to the medium, and the increase in activity of the three enzymes was monitored. Control cultures, grown in the presence of both co-inducers, were also monitored in order to obtain the relative induction of each enzyme at each sampling time. Ethanolamine ammonia-lyase and CoA-dependent aldehyde dehydrogenase exhibited induction time courses which were closely similar (Figs 1 and 2), even to the lag in the induction of both enzymes exhibited when vitamin $B_{12}$ was added (Fig. 2). Possible reasons for this lag include the time required for the conversion of vitamin $B_{12}$ to the true co-inducer, coenzyme $B_{12}$, or that required for the induction of the $B_{12}$-lyase and CoA-dependent aldehyde dehydrogenase (Figs 1 and 2). Induction of all three enzymes by ethanolamine and vitamin $\mathbf{B}_{12}$ was inhibited by chloramphenicol $\left(500 \mu \mathrm{g} \mathrm{ml}^{-1}\right)$ or rifampicin $\left(25 \mu \mathrm{g} \mathrm{ml}^{-1}\right)$, indicating an induction requirement for both transcription and translation.

Molecular exclusion chromatography of cell-free extracts from cultures of strain NCIB 8114 grown in the presence of ethanolamine and vitamin $B_{12}$ resulted in one peak of ethanolamine 


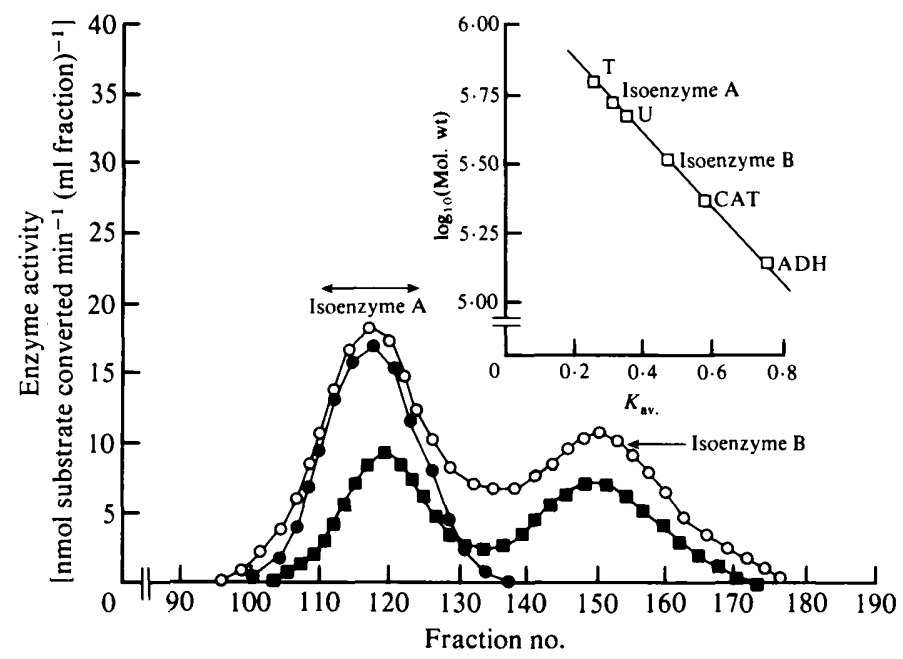

Fig. 3. Elution profile from Bio-Gel A-1.5m of a sample ( $100 \mathrm{mg}$ protein) of a cell-free extract from a culture of $E$. coli strain NCIB 8114 grown in the presence of ethanolamine $\left(1 \mathrm{~g} \mathrm{l}^{-1}\right)$ and vitamin $\mathrm{B}_{12}$ $\left(40 \mu \mathrm{g} \mathrm{l}^{-1}\right)$. Fractions (1 ml volume) were assayed for activity of ethanolamine ammonia-lyase $(O)$, $\mathrm{CoA}$-dependent aldehyde dehydrogenase $(\mathrm{O})$ and $\mathrm{CoA}$-independent aldehyde dehydrogenase $(\square)$. The inset illustrates calibration of the Bio-Gel column, by plotting elution volume (as $K_{\mathrm{av}}$ ) against $\log _{10}(\mathrm{~mol}$. wt) for standard molecules, namely thyroglobulin (T), urease (U), catalase (CAT) and alcohol dehydrogenase $(\mathrm{ADH})$ and subsequent calculation of molecular weights of isoenzymes $\mathrm{A}$ and $\mathrm{B}$ of $\mathrm{CoA}$ dependent aldehyde dehydrogenase. Calibration data are the mean of four replicates. Elution details are described in Methods. Arrows $(\leftrightarrow)$ denote the fractions used as the sample in Fig. 4.

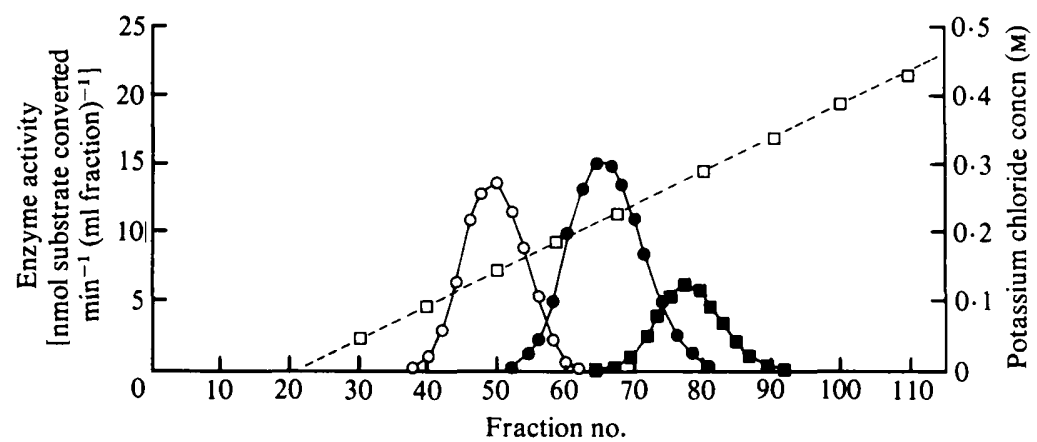

Fig. 4. Anion-exchange separation of enzymes of ethanolamine catabolism. The sample, containing molecules in the molecular weight range 500000-550000, corresponded to the fractions eluted from BioGel A-1.5m denoted by the arrows in Fig. 3. Fractions ( $5 \mathrm{ml}$ volume) were assayed for potassium chloride concentration $(\square)$ and activities of ethanolamine ammonia-lyase ( $\odot$ ), CoA-dependent aldehyde dehydrogenase $(O)$ and CoA-independent aldehyde dehydrogenase $(\square)$.

ammonia-lyase activity (at an elution volume corresponding to a spherical mol. wt of approximately 520000) and two peaks of both CoA-dependent (mol. wts 520000 and 370000 ) and CoA-independent aldehyde dehydrogenase (mol. wts 520000 and 370000 ) (Fig. 3). The fractions in which all three activities co-eluted (mol. wt 520000) were pooled and then eluted from a DEAE-cellulose anion-exchange column, resulting in a single distinct peak for each enzyme (Fig. 4). The two aldehyde dehydrogenase activities with elution volumes corresponding to a molecular weight of 370000 were also separable on DEAE-cellulose (P. W. Jones \& J. M. Turner, unpublished results). 


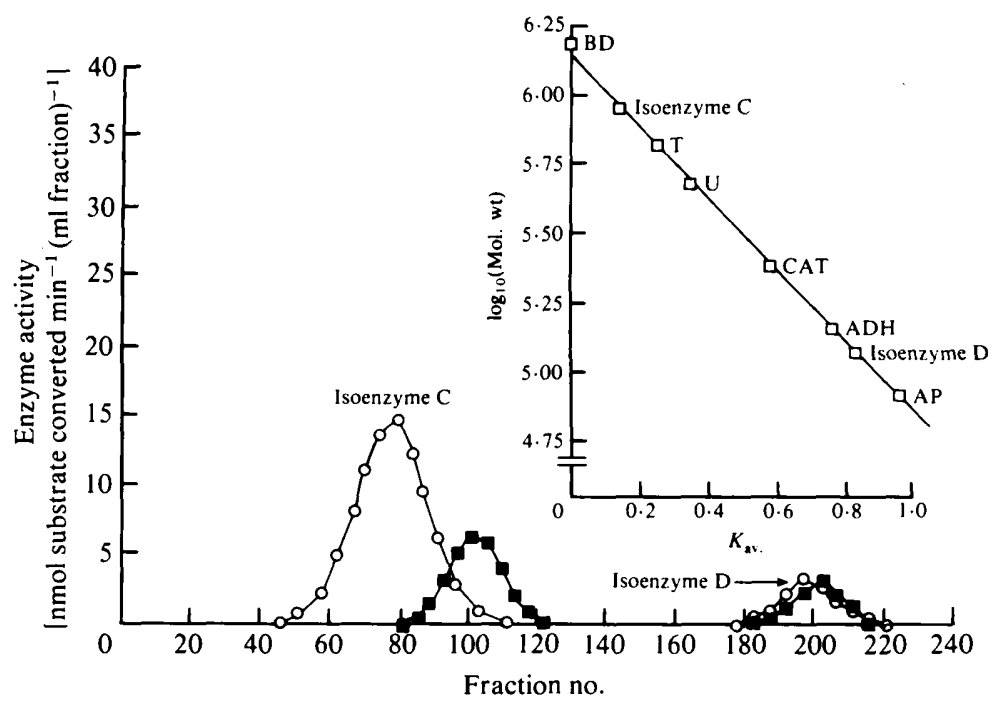

Fig. 5. Elution profile from Bio-Gel A-1.5m of a sample ( $100 \mathrm{mg}$ protein) of a cell-free extract from a culture of $E$. coli strain NCIB 8114 grown in the absence of ethanolamine and vitamin $B_{12}$ [i.e. with ammonium sulphate $\left(1 \mathrm{~g} \mathrm{l}^{-1}\right)$ as the nitrogen source]. Fractions ( $1 \mathrm{ml}$ volume) were assayed for activity of ethanolamine ammonia-lyase, $\mathrm{CoA}$-dependent aldehyde dehydrogenase $(\mathrm{O})$ and $\mathrm{CoA}$-independent aldehyde dehydrogenase ( $\square$ ). The inset is as described in Fig. 3, and elution volumes were used to calculate the molecular weights of isoenzymes $\mathrm{C}$ and $\mathrm{D}$ of CoA-dependent aldehyde dehydrogenase. Calibration data are the mean of four replicates, and elution details are described in Methods. Abbreviations are given in the legend to Fig. 3 except for BD (blue dextran) and AP (alkaline phosphatase). No ethanolamine ammonia-lyase activity was found.

Table 3. Effects on enzymes of ethanolamine catabolism in E. coli strain NCIB 11361 of different carbon and nitrogen sources

The concentrations of the variable components were as follows: ammonium sulphate, $1 \mathrm{~g} \mathrm{l}^{-1}$; ethanolamine, $1 \mathrm{~g} \mathrm{l}^{-1}$; vitamin $\mathrm{B}_{12}, 40 \mu \mathrm{g}^{-1}$; glycerol, $5 \mathrm{~g} \mathrm{l}^{-1}$; sodium acetate, $5 \mathrm{~g} \mathrm{l}^{-1}$.

\begin{tabular}{|c|c|c|c|c|}
\hline \multirow[b]{2}{*}{ Nitrogen + carbon sources } & \multicolumn{4}{|c|}{$\begin{array}{l}\text { Enzyme activities [nmol substrate converted } \mathrm{min}^{-1} \\
\qquad(\mathrm{mg} \text { protein })^{-1} \text { ] }\end{array}$} \\
\hline & $\begin{array}{l}\text { Ethanolamine } \\
\text { ammonia-lyase }\end{array}$ & $\begin{array}{c}\text { CoA-dependent } \\
\text { aldehyde } \\
\text { dehydrogenase }\end{array}$ & $\begin{array}{l}\text { CoA-independent } \\
\text { aldehyde } \\
\text { dehydrogenase }\end{array}$ & $\begin{array}{c}\text { Isocitrate } \\
\text { lyase }\end{array}$ \\
\hline Ammonium sulphate + glycerol & $97 \cdot 8$ & $106 \cdot 4$ & $11 \cdot 6$ & $0 \cdot 8$ \\
\hline $\begin{array}{l}\text { Ammonium sulphate }+ \text { glycerol } \\
+ \text { ethanolamine }+ \text { vitamin } B_{12}\end{array}$ & $112 \cdot 8$ & $123 \cdot 0$ & $25 \cdot 6$ & $0 \cdot 4$ \\
\hline $\begin{array}{l}\text { Ammonium sulphate }+ \text { sodium acetate } \\
+ \text { ethanolamine }+ \text { vitamin } B_{12}\end{array}$ & $42 \cdot 2$ & $48 \cdot 6$ & $10 \cdot 1$ & $92 \cdot 6$ \\
\hline LSD $5 \%$ & $6 \cdot 1$ & $3 \cdot 7$ & $4 \cdot 1$ & 一 \\
\hline
\end{tabular}

Elution from Bio-Gel A-1.5m of the corresponding extract from cultures grown in the absence of one or both co-inducers produced two peaks of both CoA-dependent aldehyde dehydrogenase (mol. wts 900000 and 120000) and CoA-independent aldehyde dehydrogenase (mol. wts 720000 and 120000) (Fig. 5).

Blackwell \& Turner (1978) isolated a mutant strain of E. coli (NCIB 11361) which exhibited constitutive production of ethanolamine ammonia-lyase in the absence of the co-inducers. Under these conditions, i.e. with glycerol $\left(5 \mathrm{gl}^{-1}\right)$ as the carbon source and ammonium sulphate $\left(1 \mathrm{~g} \mathrm{l}^{-1}\right)$ as the nitrogen source, cell-free extracts of this strain exhibited high levels of activity of both ethanolamine ammonia-lyase and CoA-dependent aldehyde dehydrogenase (Table 3), 


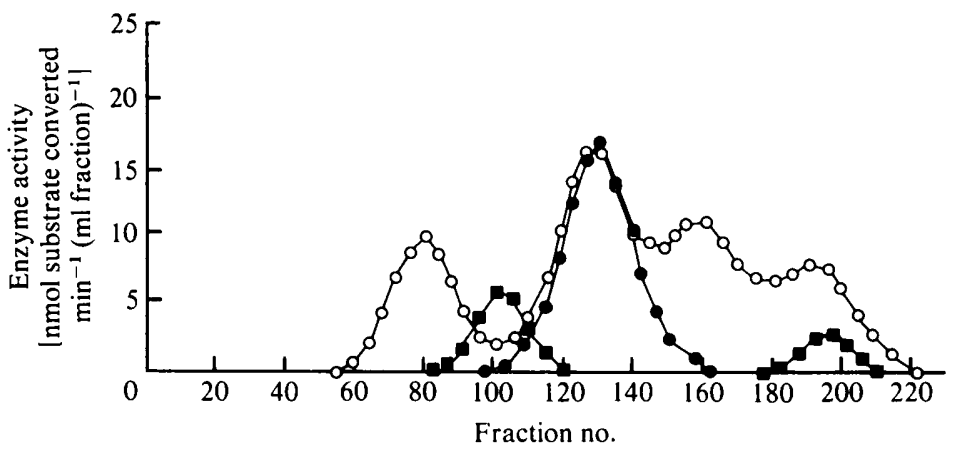

Fig. 6. Elution profile from Bio-Gel A-1.5m of a cell-free extract ( $100 \mathrm{mg}$ protein) from $E$. coli NCIB 11361 grown in the absence of ethanolamine and vitamin $B_{12}$, fractions (1 $\mathrm{ml}$ volume) being assayed for activity of ethanolamine ammonia-lyase $(O)$, CoA-dependent aldehyde dehydrogenase $(O)$ and CoA-independent aldehyde dehydrogenase $(\boldsymbol{\square})$.

corresponding to activities induced in the parental strain, NCIB 8114 (Table 1). The activity (Table 3) of CoA-independent aldehyde dehydrogenase, however, was similar to that exhibited by strain NCIB 8114 in the absence of co-inducers (Table 1). These observations were borne out by the elution profile from Bio-Gel A-1.5m of the cell-free extract, which revealed all four isoenzymes of CoA-dependent aldehyde dehydrogenase (i.e. two inducible and two repressible isoenzymes) but only the two repressible isoenzymes of $\mathrm{CoA}$-independent aldehyde dehydrogenase (Fig. 6). In the presence of both co-inducers, strain NCIB 11361 produced elution profiles of all three enzyme activities similar to that of strain NCIB 8114 (Fig. 3).

Attempts to induce synthesis of either aldehyde dehydrogenase using a range of aldehydes, including acetaldehyde, butyraldehyde, propionaldehyde and glutaraldehyde, proved unsuccessful, though tracer experiments demonstrated that the bacterial cells took up $\left[{ }^{14} \mathrm{C}\right]-$ acetaldehyde. The ethanolamine analogue DL-1-amino-propan-2-ol is known to be active as an inducer of, but not as a substrate for, ethanolamine ammonia-lyase (Blackwell \& Turner, 1978). Growth of strain NCIB 8114 in the presence of ammonium sulphate $\left(1 \mathrm{~g} \mathrm{l}^{-1}\right)$, glycerol $\left(5 \mathrm{~g} \mathrm{l}^{-1}\right)$, vitamin $B_{12}\left(40 \mu \mathrm{g} \mathrm{l}^{-1}\right)$ and 1-amino-propan-2-ol $\left(1 \mathrm{~g} \mathrm{l}^{-1}\right)$ induced activity of both ethanolamine ammonia-lyase and inducible CoA-dependent aldehyde dehydrogenase isoenzymes, as well as a smaller increase in the activity of CoA-independent aldehyde dehydrogenase (Table 1). The presence of inducible isoenzymes and the absence of repressible isoenzymes of CoAdependent aldehyde dehydrogenase in strain NCIB 8114 grown on this medium was demon: strated by elution of the corresponding cell-free extract from Bio-Gel A-1.5m.

\section{DISCUSSION}

Although previous studies had failed to detect CoA-independent aldehyde dehydrogenase activity in E. coli (Shukla \& Turner, 1980), activity of this enzyme was demonstrated here under appropriate growth conditions. In general, however, our inter-strain data support the earlier findings from inter-species studies that a close-relationship exists between CoA-dependent aldehyde dehydrogenase and ethanolamine ammonia-lyase (Shukla \& Turner, 1980). Growth of $E$. coli wild-type cultures (e.g. NCIB 8114) in the presence of glycerol, ethanolamine and vitamin $B_{12}$ results in the deamination of ethanolamine (by ethanolamine ammonia-lyase), the resultant ammonia being used to supply the cells with nitrogen, while the acetaldehyde produced is converted to acetyl-CoA by CoA-dependent aldehyde dehydrogenase. When glycerol is absent, ethanolamine can act as the major source of both carbon and nitrogen, acetyl-CoA being further metabolized via the glyoxylate pathway as indicated by the induction of isocitrate lyase, one of the enzymes of this pathway.

During the course of these studies, a cobamide-independent pathway for the utilization of ethanolamine as a nitrogen source was identified in the $E$. coli mutant strain PDT 74. 
Cobamide-independent growth of this strain on ethanolamine as the nitrogen source resulted in the induction of high levels of CoA-independent aldehyde dehydrogenase, presumably to deal with the aldehyde formed from ethanolamine catabolism. This pathway for the catabolism of the carbon skeleton, however, appears incapable of supporting the PDT 74 culture with respect to carbon, although this strain is capable of synthesizing isocitrate lyase in the presence of exogenous acetate. This cobamide-independent pathway of ethanolamine metabolism constitutes a route previously undescribed in $E$. coli or other bacterial species, as no evidence was found for the operation of either of the previously reported cobamide-independent pathways of ethanolamine catabolism. The characteristics of this new pathway are still under investigation. The PDT 74 data further support the theory that the product of ethanolamine catabolism by an enzyme other than ethanolamine ammonia-lyase is metabolized by the CoA-independent form of aldehyde dehydrogenase.

If ethanolamine ammonia-lyase and inducible CoA-dependent aldehyde dehydrogenase are successive enzymes in the pathway of ethanolamine catabolism in $E$. coli, it is likely that a genetic mechanism exists for co-ordination of their synthesis. This hypothesis is supported by the data presented here. The requirements for and dynamics of induction of both enzyme activities are similar, induction of ethanolamine ammonia-lyase and inducible CoA-dependent aldehyde dehydrogenase being effected by concerted action of ethanolamine and coenzyme $B_{12}$. The production of ethanolamine ammonia-lyase and inducible CoA-dependent aldehyde dehydrogenase by mutant strain NCIB 11361 grown in the absence of the co-inducers supports the hypothesis that these two enzyme activities are under common genetic control. Chromatographic separation on Bio-Gel A-1.5m and DEAE-cellulose demonstrated that the two activities are due to distinct proteins. As the two enzymes catalyse successive steps in the pathway of ethanolamine catabolism, it is possible that the aldehyde dehydrogenase was induced by the aldehyde product of ethanolamine ammonia-lyase activity. The failure of exogenously-supplied aldehydes to induce aldehyde dehydrogenase activity, and the production of inducible CoAdependent aldehyde dehydrogenase in the absence of aldehyde production by ethanolamine ammonia-lyase (e.g. in the case of strain NCIB 11361 grown in the absence of co-inducers, and of strain NCIB 8114 supplied with 1-amino-propan-2-ol as nitrogen source) serve to demonstrate that the relationship between the two enzymes is not due to sequential induction.

These data suggest that ethanolamine ammonia-lyase and inducible CoA-dependent aldehyde dehydrogenase are under a common genetic control, although it is still unclear if control is co-ordinate or parallel. Under most circumstances, a relatively constant value is obtained for the ethanolamine ammonia-lyase :inducible $\mathrm{CoA}$-dependent aldehyde dehydrogenase activity ratio, suggesting co-ordinate control.

The relationship between the inducible and repressible forms of CoA-dependent aldehyde dehydrogenase is based on the relative effects of ethanolamine and coenzyme $B_{12}$, which act as co-repressors of the repressible isoenzymes and as co-inducers of the inducible isoenzymes. Thus, although ethanolamine ammonia-lyase and inducible aldehyde dehydrogenase may be controlled in a single operon, repressible CoA-dependent aldehyde dehydrogenase will be under a control system separate from that of the other two enzymes. The four-peak CoA-dependent aldehyde dehydrogenase profile exhibited by strain NCIB 11361 in the absence of co-inducers could have been due to a mixed culture of NCIB 11361 and revertants to the parental strain NCIB 8114. Cultures derived from a single colony, however, still produced the four-peak profile, and no evidence was obtained to support the theory of an excessively high frequency of reversion in NCIB 11361.

Like CoA-dependent aldehyde dehydrogenase, CoA-independent aldehyde dehydrogenase also consisted of four isoenzymes, two repressible and two inducible by the concerted action of ethanolamine and coenzyme $B_{12}$. Three of the four isoenzymes of CoA-independent aldehyde dehydrogenase co-eluted from Bio-Gel A-1.5m with isoenzymes of CoA-dependent aldehyde dehydrogenase but these could be separated by anion-exchange chromatography, indicating that no structural relationship existed between CoA-dependent and CoA-independent aldehyde dehydrogenases. The lack of effect on CoA-independent, as opposed to CoA-dependent aldehyde dehydrogenase, of the regulatory mutation carried by strain NCIB 11361 demon- 
strated that, though superficially the two enzymes have similar induction requirements, there is no common regulation between CoA-dependent aldehyde dehydrogenase (and hence ethanolamine ammonia-lyase) and CoA-independent aldehyde dehydrogenase.

The work presented here was supported by the Medical Research Council. We are grateful to Ms Kerrie Harvey for valuable technical assistance.

\section{REFERENCES}

BlackWell, C. M. \& TURner, J. M. (1978). Formation of coenzyme $B_{12}$-dependent ethanolamine ammonia-lyase and its concerted induction in Escherichia coli. Biochemical Journal 176, 751-757.

Blackwell, C. M., SCARLetT, F. A. \& TURNer, J. M. (1976). Ethanolamine catabolism by bacteria, including Escherichia coli. Biochemical Society Transactions 4, 495-497.

BlackWell, C. M., Scarlett, F. A. \& Turner, J. M. (1977). Microbial metabolism of amino alcohols. Control of formation and stability of partiallypurified ethanolamine ammonia-lyase in Escherichia coli. Journal of General Microbiology 98, 133-139.

BRADBEer, C. (1965). The clostridial formations of choline and ethanolamine. I. Preparation and properties of cell-free extracts. Journal of Biological Chemistry 240, 4669-4674.

DiXoN, G. H. \& Kornberg, H. L. (1959). Assay methods for key enzymes of the glyoxylate cycle. Biochemical Journal 72, 3P.

Gornall, A. G., BARdawill, C. J. \& David, M. M. (1949). Determination of serum proteins by means of the biuret reaction. Journal of Biological Chemistry 177, 751-766.

JAKOBY, W. B. (1958). Aldehyde oxidation. I. Dehydrogenase from Pseudomonas fuorescens. Journal of Biological Chemistry 232, 75-87.

JONES, A. \& TURNER, J. M. (1971). Microbial metabo- lism of amino alcohols via aldehydes. Journal of General Microbiology 67, 379-381.

JONES, A. \& TURNER, J. M. (1973). 1-Aminopropan-2ol and ethanolamine metabolism via propionaldehyde and acetaldehyde in a species of Pseudomonas. Biochemical Joumal 134, 167-182.

NARROD, S. A. \& JAKOBY, W. B. (1964). Metabolism of ethanolamine. An ethanolamine oxidase. Journal of Biological Chemistry 239, 2189-2193.

Pennington, S. J., Jones, P. W. \& Turner, J. M. (1981). The adenosylcobalamin-dependent ethanolamine ammonia-lyase of Escherichia coli. Biochemical Society Transactions 9, 447.

RudolPh, F. B., Purich, D. L. \& Fromm, H. J. (1968). Coenzyme A-linked aldehyde dehydrogenase from Escherichia coli I. Partial purification, properties and kinetic studies of the enzyme. Journal of Biological Chemistry 243, 5539-5545.

SCARLetT, F. A. \& TURNeR, J. M. (1976). Microbial metabolism of amino alcohols. Ethanolamine catabolism mediated by coenzyme $\mathbf{B}_{12}$-dependent ethanolamine ammonia-lyase in Escherichia coli and Klebsiella aerogenes. Journal of General Microbiology 95, 173-176.

ShUKLA, S. D. \& TURNer, J. M. (1980). Biosynthetic utilization of ethanolamine for lipid synthesis by bacteria. Biochemical Journal 186, 13-19. 